\title{
Improvement of cold stress resistance via free radical scavenging ability and promoted water status and photosynthetic capacity of gallic acid in soybean leaves
}

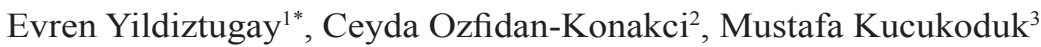

${ }^{1}$ Selcuk University, Faculty of Science, Department of Biotechnology, 42250, Selcuklu, Konya, Turkey. ${ }^{2}$ Necmettin Erbakan University, Faculty of Science, Department of Molecular Biology and Genetics, 42090, Meram, Konya, Turkey. ${ }^{3}$ Selcuk University, Faculty of Science, Department of Biology, 42250, Selcuklu, Konya, Turkey. *Corresponding author: eytugay@selcuk.edu.tr

\begin{abstract}
Plant polyphenols exhibit a wide variety of biological activities such as antimutagenicity, anticarcinogenicity and antioxidative activity. There is no report whether gallic acid (GLA), a naturally occurring plant phenol, is able to activate the plant defense system under cold stress. For this purpose, after soybean (Glycine max) was hydroponically grown for 3 weeks, seedlings were treated with gallic acid (GLA; 1 and $2 \mathrm{mM}$ ) and cold stress (5 ${ }^{\circ} \mathrm{C}$ and $10^{\circ} \mathrm{C}$ ) and GLA and stress combination for $72 \mathrm{~h}$. The inhibition in growth, water content (RWC), osmotic potential $\left(\Psi_{\Pi}\right)$ and photosynthetic activity observed under stress and was more at the lowest temperature. Stress also elicited the accumulation of proline (Pro) only at $5{ }^{\circ} \mathrm{C}$. While the capacity to maintain high growth, RWC, $\Psi \Pi$ and photosynthetic efficiency was observed in GLA-treated plants under stress, Pro accumulation could not achieve with GLA plus stress. Any increase in total activities of superoxide dismutase (SOD) and catalase (CAT) induced by stress treatments determined. The lower cold stress caused an increase in the activities of ascorbate peroxidase (APX), glutathione reductase (GR) and NADPH oxidase (NOX). GLA treatment under stress (especially at $5{ }^{\circ} \mathrm{C}$ ) could supply the increased activities of SOD, CAT, APX and GR. Also, exogenous GLA application to stress-treated plants increased the enzyme activities in ascorbate-glutathione cycle such as monodehydroascorbate reductase (MDHAR) and dehydroascorbate reductase (DHAR) and, contents of ascorbate (AsA) and glutathione. After GLA application under stress, it is observed reduction in hydrogen peroxide $\left(\mathrm{H}_{2} \mathrm{O}_{2}\right)$ and the levels of lipid peroxidation (TBARS), and induction of hydroxyl radical $\left(\mathrm{OH}^{\bullet}\right)$ scavenging. Our results suggest that GLA is a potent inducer for induction of the scavenging activity of radicals as well as effectively usage of water status and photosynthetic capacity.
\end{abstract}

Keywords: Antioxidant enzyme, Cold stress, Gallic acid, Glycine max, Water content 


\section{Introduction}

Cold stress, which includes both chilling injury (less than $20^{\circ} \mathrm{C}$ ) and freezing injury (less than $0{ }^{\circ} \mathrm{C}$ ), is one of the most significant abiotic stresses of agricultural plants. This stress limits the growth and yield of many economically important crop plants (Bunn et al., 2009), such as rice, corn, tomato and soybean. Temperature dependent reduction of metabolic activities in plants includes limitations of photosynthesis, which in turn contribute forming excess excitation energy. Cold stress enhances the production of reactive oxygen species (ROS; superoxide anion radical, hydrogen peroxide $\left(\mathrm{H}_{2} \mathrm{O}_{2}\right)$ and hydroxyl radical $\left.\left(\mathrm{OH}^{\bullet}\right)\right)$ in cellular compartments such as chloroplasts, peroxisomes, and mitochondria (Jajic et al., 2015). The continuous generation in non-toxic levels and scavenging of ROS acts as a long distance signal via a cell to cell communication but, high ROS accumulation ultimately leads to oxidative stress, which affects essential plant metabolic activities and cell viability (Bose et al., 2014). Since oxidative stress is accompanied with cold stress, the ability to activate protective mechanisms, such as an increase in the activity of scavenging enzymes, is vital for plant cold tolerance. The primary antioxidants (antioxidant enzymes and low molecular-weight antioxidants, such as ascorbic acid and glutathione) are scavenged stress-induced radicals under a severe excess of radiant energy (Jajic et al., 2015).

Phenolic compounds are widely distributed in plants and they are mainly involved in the cell defense system against free radicals under unfavorable environmental influences, including salinity and drought (Selmar and Kleinwächter, 2013). For example, Pennycooke et al. (2005) reported that chilling stress is led to elevated total phenolic content and antioxidant capacity in petunia. A number of phenolic compounds with strong antioxidant and antimicrobial activities have been identified in plants (Selmar and Kleinwächter, 2013).
One of the plant phenolic metabolites is tannins. Tannins form a diverse group that includes the widely distributed different types of tannins, hydrolysable or condensed tannins (Mandal et al., 2010). Gallic acid (GLA), one of hydrolysable tannins, is capable of inducing apoptosis in animal cells and of generating oxygen radicals, either alone or in the presence of transition metal ions (Jajic et al., 2015). The nature of polyhydroxyls groups of GLA can be related to their antioxidant action. The reported studies generally focus on neuroprotective capacity, anticancer and gastroprotective activities of GLA application in animals (Selmar and Kleinwächter, 2013).

Soybean (Glycine max) is a nutritionally important crop which provides an abundant source of oil and protein for worldwide human consumption. With an average protein content of $40 \%$, soybean has the highest protein content of all food crops, and its oil content of $20 \%$ is second only to that of groundnut among the leguminous foods (Toorchi et al., 2009). Low temperatures, however, cause significant losses in soybean production. Before and during the flowering period, low temperatures influence seed yield due to poor pod formation and seed filling. Night temperatures below $15{ }^{\circ} \mathrm{C}$ limit a wide range of physiological processes including photosynthesis, growth, development and yield (van Heerden et al., 2003).

There is no published scientific report on the possible preventive roles of GLA against cold stress in plants. Considering all of these points, this study was intended to examine the effects of exogenous GLA application on alleviation of growth, water status and peroxidation damage on lipids induced by cold stress and determined whether its preventive effect is modulated via enzymatic/non-enzymatic antioxidant mechanisms being tolerance markers of stress in soybean leaves. 


\section{Material and Methods}

\subsection{Plant materials and experimental design}

Seeds of Glycine max L. cv mitchell obtained from Directorate of Trakya Agricultural Research Institute. The seeds were surface-sterilized in 5\% sodium hypochlorite for $10 \mathrm{~min}$, rinsed five times with sterile distilled water and then allowed to germinate on the double-layer filter paper wetted distilled water. Germinated soybean seedlings were transferred to half strength Hoagland solution and were grown under controlled conditions $(16 / 8 \mathrm{~h}$ light/dark regime at 24 ${ }^{\circ} \mathrm{C}, 70 \%$ relative humidity and $350 \mu \mathrm{mol} \mathrm{m}{ }^{-2} \mathrm{~s}^{-1}$ photosynthetic photon flux density). The seedlings were grown in hydroponic culture containing this solution for $21 \mathrm{~d}$ and the various concentrations of gallic acid (GLA; 1 and $2 \mathrm{mM}$ ) was treated alone or in combination with cold stress $\left(5^{\circ} \mathrm{C}\right.$ and $\left.10{ }^{\circ} \mathrm{C}\right)$. Plants were harvested after $72 \mathrm{~h}$ of treatment and then the leaves stored at $-86{ }^{\circ} \mathrm{C}$ until further analyses.

\subsection{Determination of growth, water content, osmotic} potential, leaf water loss and proline Content

Six random plants for each group were separated to leaf fractions after $72 \mathrm{~h}$ of stress. Leaf dry weights (DW) were dried at $706^{\circ} \mathrm{C}$ for $72 \mathrm{~h}$ and were measured to calculate the relative growth rate (RGR). After harvest on $72 \mathrm{~h}$, six leaves were obtained from soybean and their fresh weight (FW) was determined. The leaves were floated on de-ionised water for $6 \mathrm{~h}$ and the turgid tissue was blotted dry prior to determining turgid weight (TW). DW was determined after oven drying at $70{ }^{\circ} \mathrm{C}$. The leaf relative water content (RWC) was calculated. Leaves were extracted by crushing the material with a glass rod. Leaf osmotic potential (Чп) was measured by Vapro Vapor pressure
Osmometer 5600. The data was collected from six sample leaves per replicate.

According to Ozgur et al. (2014), for determination of leaf water loss as an indicator of stomatal conductance, leaves were detached from the plants and their weights were immediately measured. After $10 \mathrm{~min}$ in the growth chamber, weights of the leaves were measured again and this procedure was repeated again at 20 min. Leaf water loss was calculated from these values as a percentage of the original weight of the leaves. Six leaf replicates were used for this analysis from different plants in each treatment group.

Pro content was done according to Bates et al. (1973). The leaves were homogenized in 3\% sulphosalicylic acid and homogenate was filtered through filter paper. After addition of acid ninhydrin and glacial acetic acid, the mixture was heated at $100{ }^{\circ} \mathrm{C}$. The mixture was extracted with toluene and the absorbance of fraction with toluene aspired from liquid phase was measured at $520 \mathrm{~nm}$.

\subsection{Determination of photosynthetic parameters}

A Fluorescence Monitoring System FMS2 was used for determination of chlorophyll fluorescence. The maximum quantum yields in the dark-adapted state (Fv/Fm), the actual quantum yields in the light-adapted steady state (ФPSII), the coefficients of photochemical quenching (qP) and the non-photochemical quenching values (NPQ) were performed.

\subsection{Determination of ROS accumulation}

Determination of $\mathrm{H}_{2} \mathrm{O}_{2}$ content was performed according to Ozgur et al. (2014) with minor revision. Leaves were homogenized in cold acetone and centrifuged at $3000 \times \mathrm{g}$ at $4{ }^{\circ} \mathrm{C}$ for $10 \mathrm{~min}$. The supernatant was mixed with titanium reagent and then ammonium hydroxide was added to precipitate the 
titanium-peroxide complex. The reaction mixture was centrifuged at $16000 \times \mathrm{g}$ at $4{ }^{\circ} \mathrm{C}$ for $10 \mathrm{~min}$, and the pellet was washed with cold acetone. The pellet was dissolved in $1 \mathrm{M} \mathrm{H}_{2} \mathrm{SO}_{4}$. The absorbance of the solution was measured at $410 \mathrm{~nm} . \mathrm{H}_{2} \mathrm{O}_{2}$ concentrations were calculated using a standard curve prepared with known concentrations of $\mathrm{H}_{2} \mathrm{O}_{2}$. $\mathrm{OH}^{\cdot}$ scavenging activity was determined according to Chung et al. (1997), with minor changes. All solutions were prepared fresh during the analysis. Competition between deoxyribose and the sample for $\mathrm{OH}^{\cdot}$ generated from the $\mathrm{Fe}^{3+}$ / ascorbate/EDTA $/ \mathrm{H}_{2} \mathrm{O}_{2}$ system was measured to determine the $\mathrm{OH}^{*}$ scavenging activity. The reaction mixture contained $0.3 \mathrm{~mL}$ of $20 \mathrm{mM} \mathrm{Na}$-phosphate buffer (pH 7.0), $0.15 \mathrm{~mL}$ of $10 \mathrm{mM}$ 2-deoxyribose, $0.15 \mathrm{~mL}$ of $10 \mathrm{mM} \mathrm{FeSO}_{4}, 0.15 \mathrm{~mL}$ of $10 \mathrm{mM}$ EDTA, 0.15 $\mathrm{mL}$ of $10 \mathrm{mM} \mathrm{H}_{2} \mathrm{O}_{2}, 0.525 \mathrm{~mL} \mathrm{H} \mathrm{H}_{2} \mathrm{O}$, and $0.075 \mathrm{~mL}$ sample. The mixture was incubated at $37{ }^{\circ} \mathrm{C}$ for $2 \mathrm{~h}$. A mixture of $0.75 \mathrm{~mL}$ of $2.8 \%(\mathrm{w} / \mathrm{v})$ trichloroacetic acid and $0.75 \mathrm{~mL}$ of $1.0 \%(\mathrm{w} / \mathrm{v})$ thiobarbituric acid in $50 \mathrm{mM} \mathrm{NaOH}$ was added to the test tubes and boiled for $20 \mathrm{~min}$. After the mixture cooled, absorbance was measured at $520 \mathrm{~nm}$ against a blank solution. The $\mathrm{OH}^{*}$ scavenging activity was calculated using the following formula:

$\mathrm{OH}^{*}$ scavenging activity $(\%)=\left[\left(\mathrm{A}_{\circ}-\mathrm{A}_{1}\right) / \mathrm{A}_{\mathrm{o}}\right] \times 100$, where $A_{0}$ was the absorbance of the blank and $A_{1}$ the absorbance of the sample.

\subsection{Enzyme extraction and determination of isozyme and/or enzyme compositions}

For protein and enzyme extractions, $0.5 \mathrm{~g}$ of each sample was ground to a fine powder using liquid nitrogen and then homogenized in $50 \mathrm{mM}$ Tris- $\mathrm{HCl}(\mathrm{pH} 7.8)$ containing $0.1 \mathrm{mM}$ ethylenediaminetetraacetic acid (EDTA), $0.2 \%$ Triton X-100, $1 \mathrm{mM}$ phenylmethyl- sulfonyl fluoride and $2 \mathrm{mM}$ dithiothreitol (DTT). For APX activity determination, $5 \mathrm{mM}$ ascorbate (AsA) was added to the homogenization buffer, and $2 \%$ polyvinylpyrrolidone (PVP) was used instead of DTT. Samples were centrifuged at $14000 \times \mathrm{g}$ for $30 \mathrm{~min}$ and supernatant was used for the determination of enzyme activities. All spectrophotometric analyses were conducted on a Shimadzu spectrophotometer (UV 1800). Samples containing equal amounts of protein $(40 \mu \mathrm{g})$ were subjected to non-denaturing polyacrylamide gel electrophoresis (PAGE). SOD activity was detected by Ozgur et al. (2014) with minor modification. The units of activity for each SOD isozyme were calculated by running a SOD standard from bovine liver (Sigma Chemical Co., St. Louis, MO, USA). The total SOD (EC 1.15.1.1) activity assay used spectrophotometric analysis at $560 \mathrm{~nm}$ to measure the inhibition of the photochemical reduction of nitro blue tetrazolium (NBT). One unit of specific enzyme activity was defined as the quantity of SOD required to produce a $50 \%$ inhibition of NBT reduction.

After electrophoresis of samples containing $40 \mu \mathrm{g}$ protein, CAT isozymes were detected according to Ozgur et al. (2014). The electrophoretic separation was performed on non-denaturing polyacrylamide gels, using a $10 \%(\mathrm{w} / \mathrm{v})$ separating gel under constant current $(30 \mathrm{~mA})$. The gels were incubated in $0.01 \%(\mathrm{v} / \mathrm{v})$ $\mathrm{H}_{2} \mathrm{O}_{2}$ for 15 min, washed twice with distilled water, and then incubated for $20 \mathrm{~min}$ in staining solution containing $1 \%(\mathrm{w} / \mathrm{v}) \mathrm{FeCl}_{3}$ and $1 \%(\mathrm{w} / \mathrm{v}) \mathrm{K}_{3} \mathrm{Fe}\left(\mathrm{CN}_{6}\right)$. Total CAT (EC 1.11.1.6) activity measured the initial rate of $\mathrm{H}_{2} \mathrm{O}_{2}$ disappearance at $240 \mathrm{~nm}$. The decrease in absorption was followed for $3 \mathrm{~min}$, and one unit of CAT was defined as $1 \mathrm{mmol}_{2} \mathrm{O}_{2}$ decomposed $\mathrm{min}^{-1} \mathrm{~mL}^{-1}$. POX isozymes were detected according to Ozgur et al. (2014). Electrophoretic separation of samples containing $20 \mu \mathrm{g}$ protein was performed on non-denaturing polyacrylamide under constant current (30 $\mathrm{mA}$ ). The gels were incubated for $30 \mathrm{~min}$ at $25^{\circ} \mathrm{C}$ in 
$200 \mathrm{mM}$ sodium acetate buffer $(\mathrm{pH}$ 5.0) containing $1.3 \mathrm{mM}$ benzidine and $3 \%(\mathrm{v} / \mathrm{v}) \mathrm{H}_{2} \mathrm{O}_{2}$. The gels were stored in $7 \%(\mathrm{v} / \mathrm{v})$ acetic acid until the assay was carried out. Total POX (EC 1.11.1.7) activity was based on the method described by Ozgur et al. (2014). The increase in the absorbance at $465 \mathrm{~nm}$ was followed for $3 \mathrm{~min}$. One unit of POX activity was defined as mmol $\mathrm{H}_{2} \mathrm{O}_{2}$ decomposed $\mathrm{min}^{-1} \mathrm{~mL}^{-1}$.

Electrophoretic APX separation was performed according to Ozgur et al. (2014) with minor revisions. Non-denaturing PAGE was carried out at $4{ }^{\circ} \mathrm{C}$ in $7.5 \%$ $(\mathrm{w} / \mathrm{v})$ polyacrylamide mini slab gels $(8 \mathrm{~cm} \times 10 \mathrm{~cm})$ supported by $10 \%(\mathrm{v} / \mathrm{v})$ glycerol. Before the samples (15 $\mu \mathrm{g}$ protein) were loaded, gels were equilibrated with running buffer containing $2 \mathrm{mM}$ AsA for $30 \mathrm{~min}$ at $4{ }^{\circ} \mathrm{C}$. Subsequently, electrophoresis gels were incubated in $50 \mathrm{mM} \mathrm{K}$-phosphate buffer ( $\mathrm{pH}$ 7.0) containing $2 \mathrm{mM}$ AsA for $20 \mathrm{~min}$ and then were transferred to solutions containing $50 \mathrm{mM} \mathrm{K}$-phosphate buffer $(\mathrm{pH}$ 7.8), $4 \mathrm{mM}$ AsA, and $2 \mathrm{mM} \mathrm{H}_{2} \mathrm{O}_{2}$ for $20 \mathrm{~min}$. The gels were washed in the buffer for $1 \mathrm{~min}$ and submerged in a solution of $50 \mathrm{mM} \mathrm{K}$-phosphate buffer ( $\mathrm{pH}$ 7.8) containing $28 \mathrm{mM} \mathrm{N}, \mathrm{N}, \mathrm{N}, \mathrm{N}$-tetramethylethylenediamine (TEMED) and $2.5 \mathrm{mM}$ NBT for 10-20 min with gentle agitation in the presence of light. For total APX (EC 1.11.1.11) activity, the assay depends on the decrease in absorbance at $290 \mathrm{~nm}$. The concentration of oxidized AsA was calculated by using a $2.8 \mathrm{mM}^{-1}$ $\mathrm{cm}^{-1}$ extinction coefficient. One unit of APX was defined as $1 \mathrm{mmol}$ AsA oxidized $\mathrm{min}^{-1} \mathrm{~mL}^{-1}$.

Total GR (EC 1.6.4.2) activity was measured according to Ozgur et al. (2014) with minor modification. Activity was calculated using the extinction coefficient of NADPH $\left(6.2 \mathrm{mM}^{-1} \mathrm{~cm}^{-1}\right)$. One unit of GR was defined as $1 \mathrm{mmol}$ GSSG reduced $\mathrm{min}^{-1} \mathrm{~mL}^{-1}$. NADPH oxidase (NOX) isozymes were identified by NBT reduction method as described by Ozgur et al. (2014) with minor revisions. The samples containing $40 \mu \mathrm{g}$ protein was loaded per lane. Gels were stained in $50 \mathrm{mM}$ Tris-HCl buffer (pH 7.4), $0.2 \mathrm{mM}$ NBT, 0.1 $\mathrm{mM} \mathrm{MgCl}$ and $1 \mathrm{mM} \mathrm{CaCl}_{2}$, in the dark for $20 \mathrm{~min}$. After then $0.2 \mathrm{mM} \mathrm{NADPH} . \mathrm{Na}_{4}$ was added and the appearance of blue formazan bands was observed. For total NOX (EC 1.6.3.1) activity, the assay medium contained $50 \mathrm{mM}$ Tris- $\mathrm{HCl}$ buffer ( $\mathrm{pH} 7.5$ ), $0.5 \mathrm{mM}$ XTT, $100 \mu \mathrm{M}$ NADPH. $\mathrm{Na}_{4}$ and $20 \mu \mathrm{g}$ of protein sample. After addition of NADPH, XTT reduction was followed at $470 \mathrm{~nm}$. Activity was calculated using the extinction coefficient, $2.16 \times 104$ $\mathrm{M}^{-1} \mathrm{~cm}^{-1}$. One unit of NOX was defined as $1 \mathrm{nmol}$ $\mathrm{ml}^{-1}$ XTT oxidized $\mathrm{min}^{-1}$. Gels stained for SOD, CAT, POX and APX activities were photographed with the Gel Doc XR+ System and then analyzed with Image Lab software v4.0.1 (Bio-Rad, California, USA). Known standard amounts of enzymes ( 0.5 units of SOD and CAT, and 0.2 units of POX) were loaded onto gels.

\subsection{Determination of the activity of monodehydro-} ascorbate reductase and dehydroascorbate reductase

Monodehydroascorbate reductase (MDHAR; EC 1.6.5.4) activity was assayed by the method of Miyake and Asada (1992). The reaction mixture contained $50 \mathrm{mM}$ of Hepes- $\mathrm{KOH}$ (pH 7.6), $1 \mathrm{mM}$ NADPH, $2.5 \mathrm{mM}$ AsA and 2.5 U AsA oxidase (EC 1.10.3.3) and enzyme extract. The MDHAR activity was measured by decrease in absorbance as the amount of enzyme that oxidizes $1 \mathrm{mM}$ NADPH per minute at $340 \mathrm{~nm}$. A molar extinction coefficient of $6.2 \mathrm{mM}^{-1} \mathrm{~cm}^{-1}$ was used for the calculation of enzyme activity.

Dehydroascorbate reductase (DHAR; EC 1.8.5.1) activity was measured according to Dalton et al. (1986). DHAR activity was measured by increase in absorbance at $265 \mathrm{~nm}$ due to ascorbate formation. A 


\subsection{Determination of the contents of dehydroascor- bate and ascorbate}

Soybean leaves were homogenized in $3 \mathrm{~mL}$ ice-cold $5 \%$ metaphosphoric acid containing $1 \mathrm{mM}$ EDTA using a mortar and pestle. The homogenates were centrifuged at $11500 \times \mathrm{g}$ for $15 \mathrm{~min}$ at $4{ }^{\circ} \mathrm{C}$ and the collected supernatants were used according to the method of Dutilleul et al. (2003) with modifications to determine total and reduced ascorbate (AsA). After neutralizing the supernatant with $0.5 \mathrm{M} \mathrm{K}-\mathrm{P}$ buffer ( $\mathrm{pH} 7.0$ ), the oxidized fraction was reduced with $0.1 \mathrm{M}$ dithiothreitol. Total and reduced AsA content were assayed spectrophotometrically at $265 \mathrm{~nm}$ in $100 \mathrm{mM} \mathrm{K-P} \mathrm{buf-}$ fer ( $\mathrm{pH}$ 7.0) with 1.0 U of ascorbate oxidase (AO). To calculate AsA, a specific standard curve of AsA was used. The oxidized form of ascorbate (DHA, dehydroascorbate) was measured using the formula DHA $=$ Total AsA - Reduced AsA

\subsection{Determination of the contents of glutathione and} oxidized glutathione

The glutathione (GSH) was assayed according to Paradiso et al. (2008), utilizing aliquots of supernatant neutralized with $0.5 \mathrm{M} \mathrm{K-P}$ buffer ( $\mathrm{pH} 7.0$ ). Based on enzymatic recycling, glutathione is oxidized by DTNB and reduced by NADPH in the presence of $\mathrm{GR}$, and glutathione content is evaluated by the rate of absorption changes at $412 \mathrm{~nm}$. Oxidized glutathione (GSSG) was determined after removal of GSH by 2-vinylpyridine derivatization. Standard curves with known concentrations of GSH and GSSG were used for the quantification.

\subsection{Determination of lipid peroxidation levels}

The level of lipid peroxidation was determined by thiobarbituric acid reactive substances (TBARS) according to Ozgur et al. (2014) with minor revisions. TBARS concentration was calculated from the absorbance at $532 \mathrm{~nm}$, and measurements were corrected for nonspecific turbidity by subtracting the absorbance at $600 \mathrm{~nm}$. The concentration of TBARS was calculated using an extinction coefficient of $155 \mathrm{mM}^{-1} \mathrm{~cm}^{-1}$.

\subsection{Statistical analysis}

The experiments were repeated thrice independently and each data point was the mean of six replicates. All data obtained were subjected to a one-way analysis of variance (ANOVA). Statistical analysis of the values was performed by using SPSS 20.0. Tukey's post-test was used to compare the treatment groups. Comparisons with $p<0.05$ were considered significantly different. In all the figures, the error bars represent standard errors of the means.

\section{Results}

3.2. Growth, water content, osmotic potential, leaf water loss and proline content

As shown in Figure 1A, RGR in soybean leaves decreased following cold treatment, compared to the control. The most reduction in RGR observed in $5^{\circ} \mathrm{C}$-treated leaves (decreases by 1.5 fold). Besides, addition of GLA together with cold stress decreased the negative impacts of stress on growth parameters as compared to the stress treatment alone. On the other hand, after 72 $\mathrm{h}$ of GLA treatments, $1 \mathrm{mM}$ GLA alone significantly stimulated growth in soybean (by 9\%), while there was no apparent difference in RGR between the control and the highest GLA concentration (2 mM GLA).

The presence of cold stress in the growth media decreased RWC in leaves (Figure 1B). A slight reduction in RWC was observed in the plants exposed to the lowest cold stress and it reached the minimum levels (26\%). 

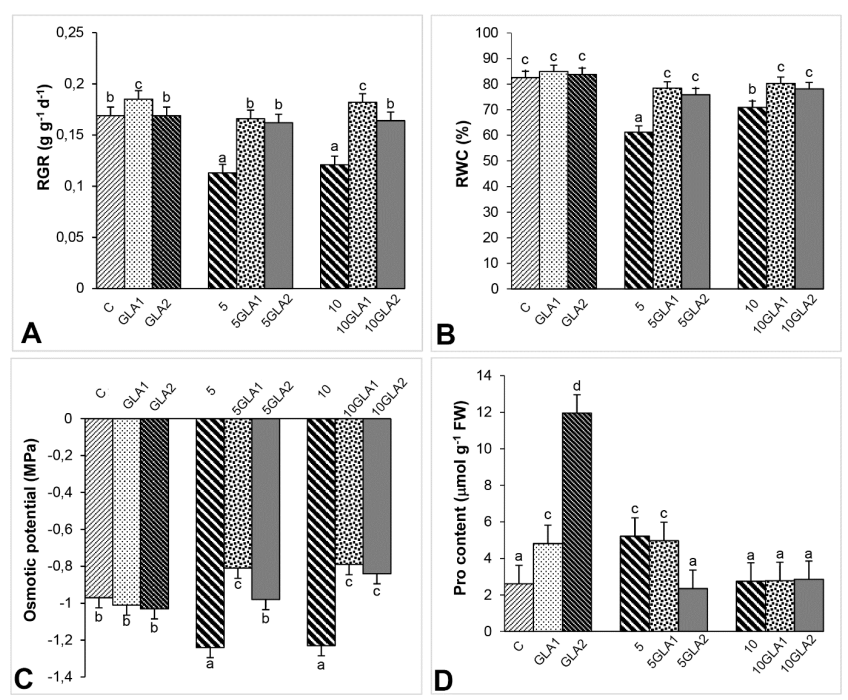

Figure 1. Effects of gallic acid (GLA1 and GLA2, 1 and $2 \mathrm{mM}$ ) on growth (RGR, A), water content (RWC, B), osmotic potential $(\Psi \Pi, \mathbf{C})$ and proline content (Pro, D) in Glycine max exposed to cold stress $\left(5^{\circ} \mathrm{C}\right.$ and $\left.10^{\circ} \mathrm{C}\right)$ for 72 hours (h)

The both GLA concentrations applied to plants exposed to cold stress restored leaf RWC. GLA treatment alone was no influence in RWC for $72 \mathrm{~h}$.

The osmotic potential $(\Psi \Pi)$ under stress conditions were significantly lower than those under the control conditions (Figure 1C). However, exogenous GLA was effective for overcoming the reduction of $\Psi$ п. The rate of increase was by $36 \%$ under GLA1 application with $10{ }^{\circ} \mathrm{C}$ when compared to the stress treatment alone. The supply of GLA to plants had no significant impact on $\Psi$ П.

Leaf water loss of stress-treated plants significantly decreased (Table 1), while the change in water loss from the leaves was similar to between control groups and GLA alone and/or GLA plus stress treatments.

As shown in Figure 1D, proline content (Pro) significantly increased only at $5{ }^{\circ} \mathrm{C}$ in comparison to the control group. Except for $5{ }^{\circ} \mathrm{C}+$ GLA2, compared to the control group, Pro content had no changes in the groups of GLA treatment under stress conditions. $5{ }^{\circ} \mathrm{C}+$ GLA2 treatment caused a decline in Pro content which was $\% 55$ reduction. On the other hand, GLA alone increased Pro content during the experimental period, the highest enhancement in Pro was by 4.6 fold in plants with GLA2 application.

\subsection{Chlorophyll fluorescence measurements}

The results of chlorophyll fluorescence parameters including the maximum efficiency of PSII photochemistry under dark-adapted (Fv/Fm), quantum yield of PSII (ФPSII), non-photochemical quenching (NPQ) and photochemical quenching coefficient (qP) were given in Figure 2. Cold stress caused a slight reduction in Fv/Fm, ФPSII and qP. However, NPQ was significantly increased at both cold treatments in comparison with the control groups. These changes in the photosynthetic parameters were markedly observed 
in the lowest cold treatment. Besides, the addition of GLA alleviated the destroy of cold stress on photosynthetic capacity and the values reached the control levels at the end of the experiment. GLA treatment alone did not notably affect Fv/Fm, NPQ and qP.

Table 1. Effects of gallic acid (GLA1 and GLA2, 1 and $2 \mathrm{mM}$ ) on leaf water loss in Glycine max exposed to cold stress $\left(5^{\circ} \mathrm{C}\right.$ and $\left.10^{\circ} \mathrm{C}\right)$ for 72 hours (h)

\begin{tabular}{llllllllll}
\hline & Control & GLA1 & GLA2 & $\mathbf{5}$ & 5GLA1 & 5GLA2 & $\mathbf{1 0}$ & 10GLA1 & 10GLA2 \\
& & & & & & & & & \\
\hline $\mathbf{1 0}$ min & $96.8 \pm 0.5$ & $95 \pm 1.2$ & $95.3 \pm 0.2$ & $90.2 \pm 0.1$ & $95.3 \pm 1$ & $91.5 \pm 1.1$ & $89.2 \pm 0.7$ & $96.9 \pm 2.8$ & $96.8 \pm 0.4$ \\
& & & & & & & & & \\
\hline $\mathbf{2 0}$ min & $91.5 \pm 0.7$ & $92 \pm 2.1$ & $93.4 \pm 1.7$ & $84.2 \pm 01.6$ & $92.4 \pm 0.9$ & $91.2 \pm 1.7$ & $85.1 \pm 1.4$ & $92.8 \pm 1.3$ & $90.9 \pm 1.6$
\end{tabular}
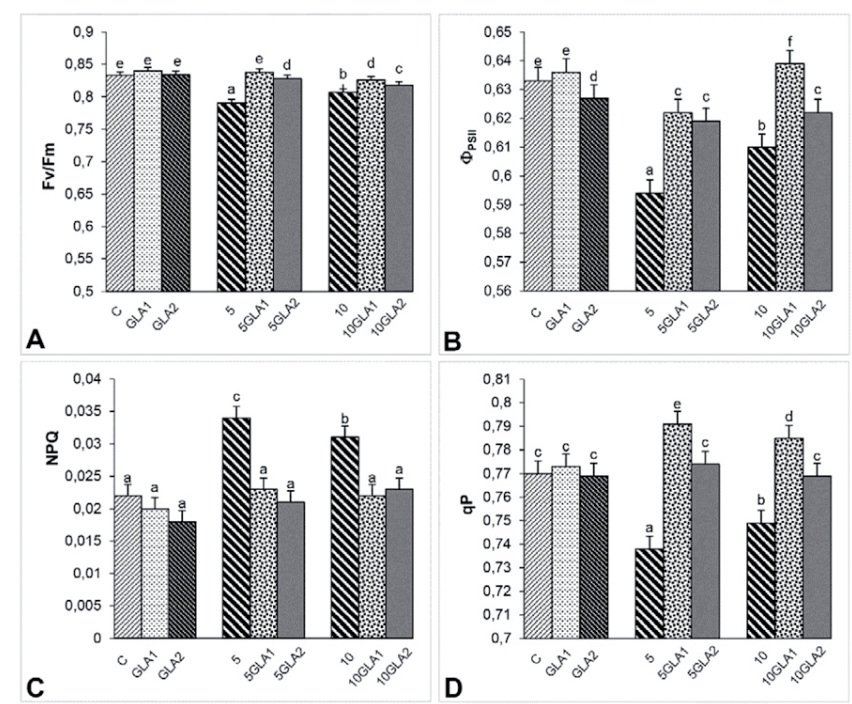

Figure 2. Effects of gallic acid (GLA1 and GLA2, 1 and $2 \mathrm{mM}$ ) on the maximum quantum yields in the darkadapted state (Fv/Fm, A), the actual quantum yields in the light-adapted steady state (ФPSII, B), the coefficients of photochemical quenching (qP, C) and the non-photochemical quenching values (NPQ, D) in Glycine max exposed to cold stress $\left(5^{\circ} \mathrm{C}\right.$ and $\left.10{ }^{\circ} \mathrm{C}\right)$ for 72 hours (h) 


\subsection{ROS content}

To determine the effect of GLA in amelioration of cold stress, $\mathrm{H}_{2} \mathrm{O}_{2}$ accumulation was analyzed (Figure $3 \mathrm{~A}$ ). $\mathrm{H}_{2} \mathrm{O}_{2}$ content in the leaves treated with $5{ }^{\circ} \mathrm{C}$ and $10{ }^{\circ} \mathrm{C}$ cold stress increased about $94 \%$ and $42 \%$ than control, respectively. Moreover, GLA application with the stress treatment slightly decreased $\mathrm{H}_{2} \mathrm{O}_{2}$ accumulation for $72 \mathrm{~h}$. After GLA treatment alone, $\mathrm{H}_{2} \mathrm{O}_{2}$ content did not change during the experimental period.

To determine the effect of GLA in amelioration of cold stress, the activity of scavenging in the leaves was analyzed (Figure 3B). The leaves with cold stress showed a weaker scavenging activity $\mathrm{OH}^{\bullet}$ for $72 \mathrm{~h}$. For example, the scavenging capacity of $\mathrm{OH}^{\bullet}$ was the lowest levels at $5{ }^{\circ} \mathrm{C}$ in leaves (by 1.2-fold decreases). Soybean with GLA under stress exhibited higher the scavenging activity of $\mathrm{OH}^{\bullet}$ compared to the stress treatment alone.

\subsection{Lipid peroxidation}

Cold stress significantly enhanced lipid peroxidation (Figure 3C). The highest enhancement observed in plants treated with $5{ }^{\circ} \mathrm{C}$ which was from $41.4 \mathrm{nmol} \mathrm{g}{ }^{-1} \mathrm{FW}$ to $63.74 \mathrm{nmol} \mathrm{g} \mathrm{g}^{-1}$ FW. However, after exogenous GLA application to stress-treated plants, soybean had significantly lower TBARS levels than the stress treatment alone. Moreover, no significant change in the TBARS content was observed in plants treated with GLA alone.

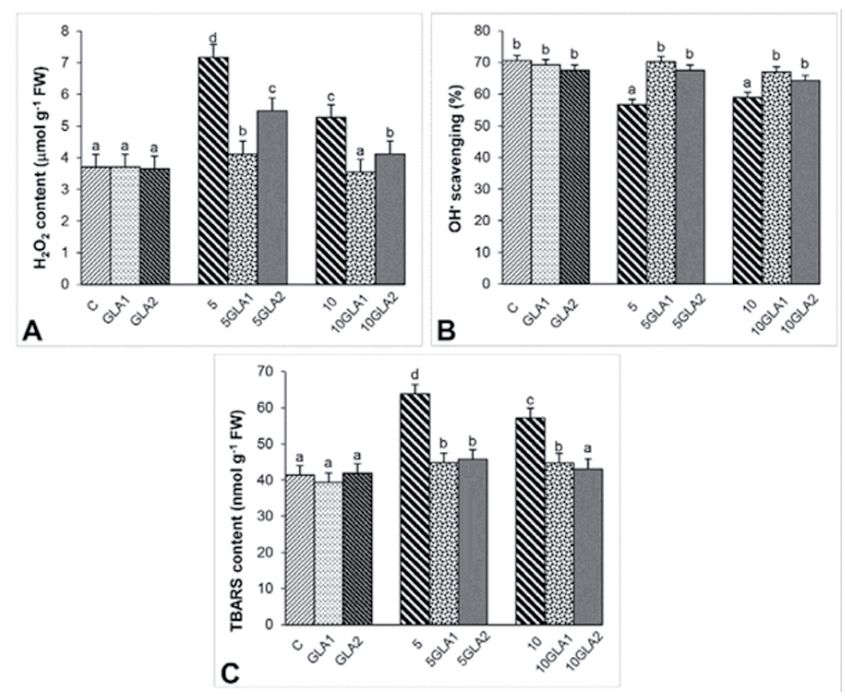

Figure 3. Effects of gallic acid (GLA1 and GLA2, 1 and $2 \mathrm{mM}$ ) on hydrogen peroxide content $\left(\mathrm{H}_{2} \mathrm{O}_{2}, \mathbf{A}\right)$, the scavenging activity of $\mathrm{OH}^{\bullet}(\mathbf{B})$ and thiobarbituric acid-reactive substances (TBARS, C) in Glycine max exposed to cold stress $\left(5^{\circ} \mathrm{C}\right.$ and $\left.10{ }^{\circ} \mathrm{C}\right)$ for 72 hours (h) 


\subsection{Antioxidant enzyme and isozyme compositions}

SOD activity bands revealed twelve SOD isozymes, including four Mn-SODs, two Fe-SODs and six $\mathrm{Cu} /$ $\mathrm{Zn}$-SODs, on non-denaturing gel in leaves of soybean in controls as well as under increasing concentrations of GLA and GLA together with cold stress (Figure 4A). In leaves, the total SOD activity was similar to the control levels at $5{ }^{\circ} \mathrm{C}$ and decreased at $10{ }^{\circ} \mathrm{C}$ (Figure 4B), as shown the intensities of $\mathrm{Fe}$ $\mathrm{SOD}$ and $\mathrm{Cu} / \mathrm{Zn}-\mathrm{SOD}$ bands (Figure 4a). Except for $5{ }^{\circ} \mathrm{C}+$ GLA2 groups, GLA application in combination with cold stress significantly increased the total SOD activity. The increased SOD activity was similar to the changes of the intensities of Mn-SOD2-4 and $\mathrm{Cu} / \mathrm{Zn}$-SODs. Moreover, no significant change in the SOD activity was observed by GLA1 alone treatment.
A single catalase activity band, CAT1, detected in enzyme preparations from soybean leaves (Figure 5A). The result of isozyme pattern of CAT enzyme was compatible with its total activity (Figure 5A-5B). All the stress treatments $\left(5{ }^{\circ} \mathrm{C}\right.$ and $\left.10{ }^{\circ} \mathrm{C}\right)$ markedly decreased total CAT activity, which reduced it by $64 \%$ and $81 \%$, respectively (Figure 5B). Comparison of the zymograms from stress treatments alone and GLA plus stress-exposed plants showed that CAT1 exhibited a slight increase at GLA + stress treatment. Similarly, zymograms gels showed that GLA application alone led to an increase of total CAT activities and the band intensity of which increased with increasing GLA concentrations. GLA or cold stress-induced changes in the isoenzyme pattern of POX in the leaves of soybean were detected by native-PAGE electrophoresis. As shown in Figure 5C, seven POX isoenzymes (POX1-7) were identified in treatment groups.

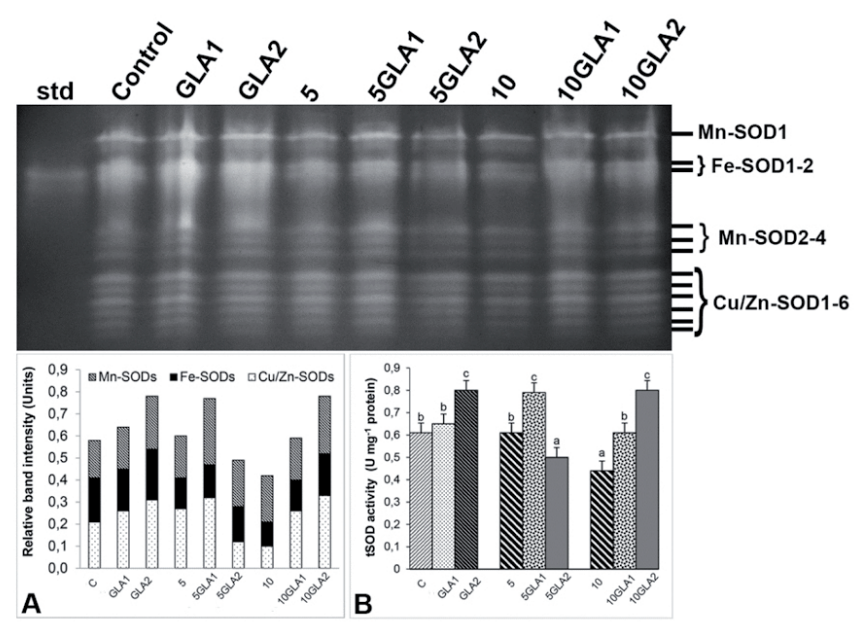

Figure 4. Effects of gallic acid (GLA1 and GLA2, 1 and $2 \mathrm{mM}$ ) on activity staining and relative contribution of SOD isozymes (A) and total SOD activity (B) in Glycine max exposed to cold stress $\left(5^{\circ} \mathrm{C}\right.$ and $\left.10{ }^{\circ} \mathrm{C}\right)$ for 72 hours (h) 


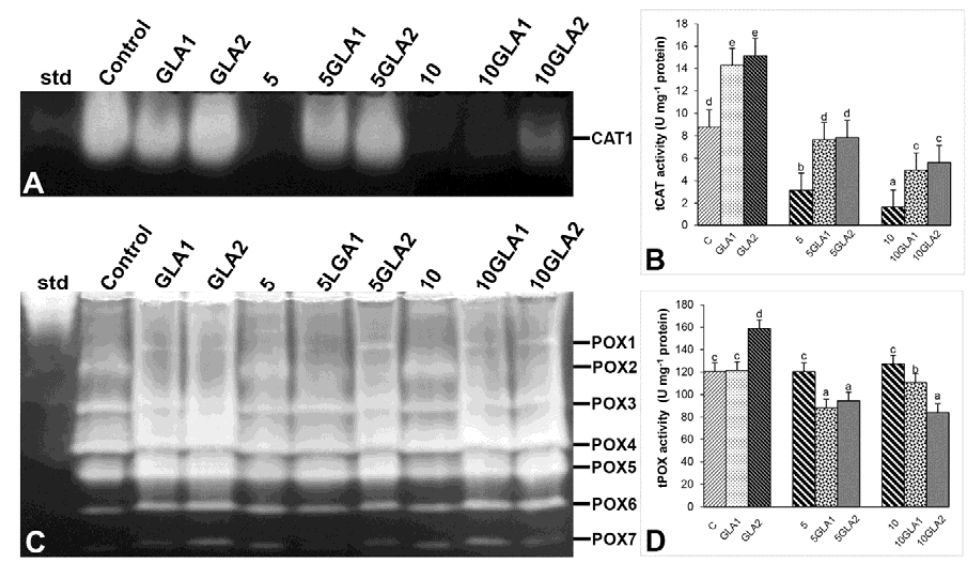

Figure 5. Effects of gallic acid (GLA1 and GLA2, 1 and $2 \mathrm{mM}$ ) on activity staining and relative contribution of CAT isozymes (A) and total CAT activity $(\mathbf{B})$, activity staining and relative contribution of POX isozymes $(\mathbf{C})$ and total POX activity (D) in Glycine max exposed to cold stress $\left(5^{\circ} \mathrm{C}\right.$ and $\left.10{ }^{\circ} \mathrm{C}\right)$ for 72 hours (h)

No differences were found in POX activity between control and low temperature treatments in soybean leaves (Figure 5D). However, the staining intensity analysis indicated that POX2 and POX4 exhibited a slight decrease in activity at stress + GLA treatments (Figure 5C), in accordance with the results obtained by the spectrophotometric analysis (Figure 5D). On the other hand, GLA1 did not alter POX activity in leaves, but this activity changed in GLA2-treated soybean leaves.

Only two APX isoenzymes (APX1-2) were determined under the conditions with/without GLA and stress treatments (Figure 6A). Cold stress increased APX activity in the leaves of soybean. Besides, this change was more pronounced under low temperature treatment plus GLA concentrations and reached maximum levels (35\%) at $5{ }^{\circ} \mathrm{C}+$ GLA2 (Figure 6B). On the other hand, APX activity was increased by $13 \%$ and $48 \%$ under GLA1 and GLA2 concentrations, respectively (Figure 6B), due to increased intensity of APX1-2 isozymes (Figure 6A).
Only $5{ }^{\circ} \mathrm{C}$ stress treatment increased the total GR activity up to $48 \%$ in soybean leaves (Figure 6C). While GLA (GLA1 and GLA2) plus $5{ }^{\circ} \mathrm{C}$ had remarkably increased the GR activity, no significant change in this activity was observed in GLA-treated plants combination with $10{ }^{\circ} \mathrm{C}$. GR activity was almost unchanged in response to GLA treatment alone.

Six isoforms of NOX were visible on the activity gels (Figure 7A). The increases of NOX activity in stress-treated leaves were higher than those of control group, enhancing the activation of NOX1, 2, 3 and 5 . The changes in isozymes were in parallel with total activities of this enzyme. However, after GLA application to stressed-seedlings, the expression of NOX isoforms was significantly weak in comparison with stress-treated groups.

Similarly, GLA application alone did not cause an increase in total NOX activity in comparison to untreated ones (Figure 7B). 

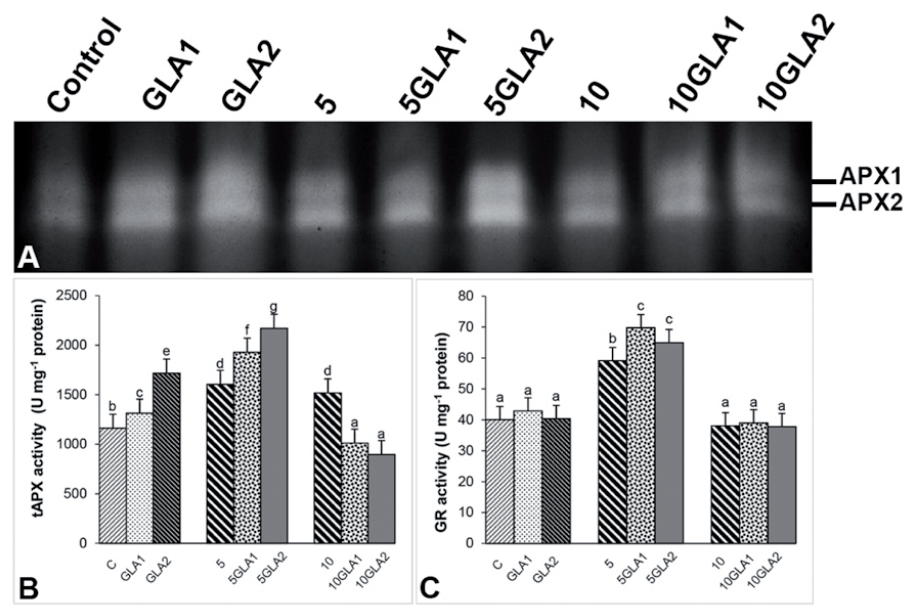

Figure 6. Effects of gallic acid (GLA1 and GLA2, 1 and $2 \mathrm{mM}$ ) on activity staining and relative contribution of APX isozymes (A), total APX activity (B) and total GR activity $(\mathbf{C})$ in Glycine max exposed to cold stress $\left(5^{\circ} \mathrm{C}\right.$ and $10{ }^{\circ} \mathrm{C}$ ) for 72 hours (h)

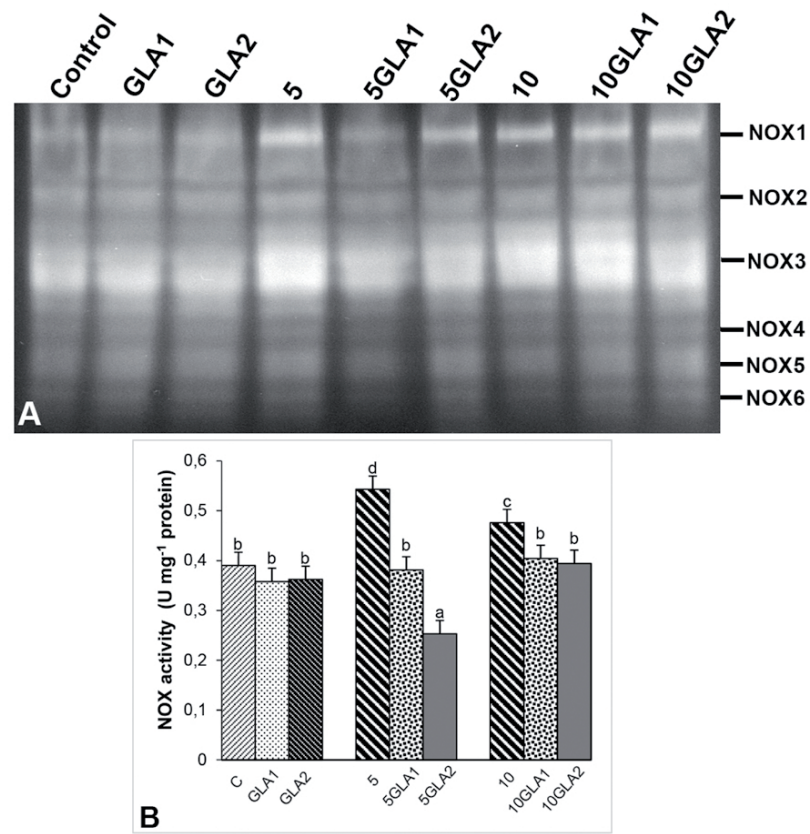

Figure 7. Effects of gallic acid (GLA1 and GLA2, 1 and $2 \mathrm{mM}$ ) on activity staining and relative contribution of NADPH oxidase (NOX) isozymes (A) and total NOX activity (B) in Glycine max exposed to cold stress $\left(5^{\circ} \mathrm{C}\right.$ and $10{ }^{\circ} \mathrm{C}$ ) for 72 hours (h) 

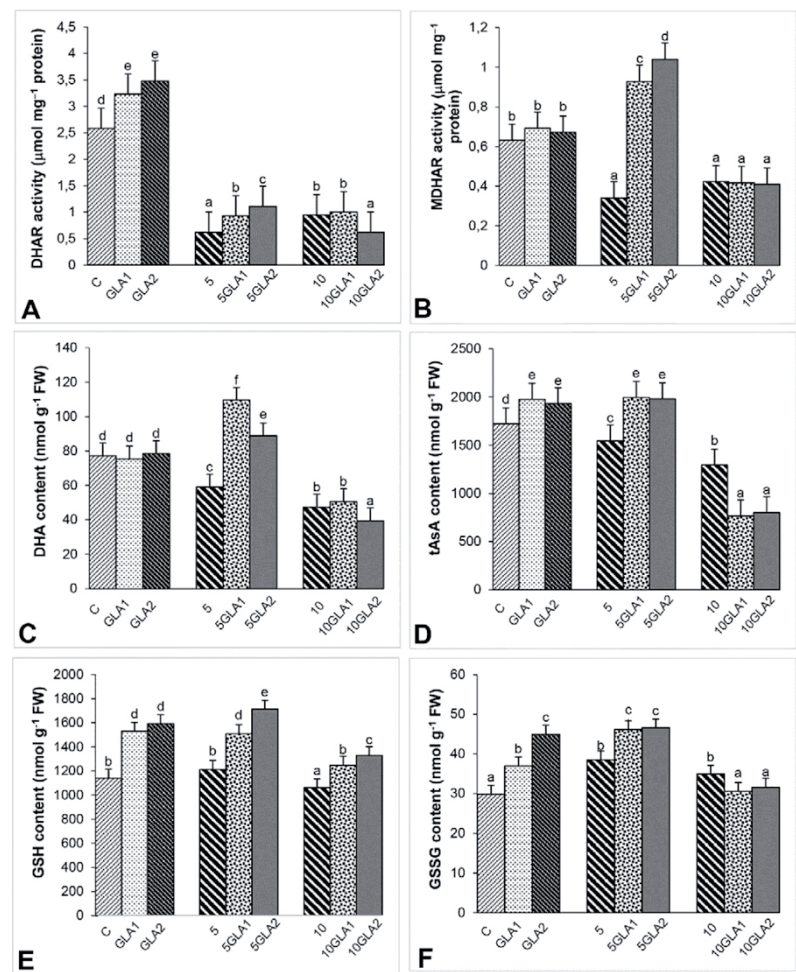

Figure 8. Effects of gallic acid (GLA1 and GLA2, 1 and $2 \mathrm{mM}$ ) on dehydroascorate reductase activity (DHAR, A), activity monodehydroascorbate reductase (MDHAR, B), dehydroascorbate content (DHA, C), total ascorbate content (AsA, D), glutathione content (GSH, E) and oxidized glutathione content (GSSG, F) in Glycine max exposed to cold stress $\left(5^{\circ} \mathrm{C}\right.$ and $\left.10^{\circ} \mathrm{C}\right)$ for 72 hours (h)

\subsection{The activity of MDHAR and MDHAR and the content of DHA, AsA, GSG and GSSG}

The activity of DHAR and MDHAR in leaves quickly decreased with increased temperature treatments (Figure 8A-8B). The maximum reduction in DHAR and MDHAR induced by stress treatments was at 5 ${ }^{\circ} \mathrm{C}$ (76\% and $46 \%$, respectively). However, the all of GLA concentrations inhibited this effect only at $5{ }^{\circ} \mathrm{C}$ treatments. For example, after $72 \mathrm{~h}$ of treatments, the activities of DHAR and MDHAR in the GLA2 + 5 ${ }^{\circ} \mathrm{C}$-treated plants were 1.8- and 3-fold higher than in those only exposed to stress alone. While exogenous GLA application alone further accelerated this increase in DHAR activity, it observed any change in MDHAR activity.

Stress caused a decrease in DHA and AsA contents in soybean leaves. For example, compared with the control groups, $39 \%$ and $25 \%$ reductions in the DHA and AsA content were observed with $10{ }^{\circ} \mathrm{C}$ treatment, respectively (Figure 8C-8D). In contrary, upon addition of GLA to $5{ }^{\circ} \mathrm{C}$-treated plants, there was a significant increase in DHA and AsA contents than stress treatment alone. On the other hand, GLA treatments alone 
caused a significant increase in AsA content. However, DHA content was similar to the control groups under GLA application alone.

The seedlings treated with cold stress $\left(5^{\circ} \mathrm{C}\right.$ and 10 ${ }^{\circ} \mathrm{C}$ ) showed $29 \%$ and $17 \%$ increases in GSSG content when compared to the control groups, respectively (Figure 8F). However, GLA treatment (GLA1 + GLA2) plus $5{ }^{\circ} \mathrm{C}$ stress resulted in more remarkable increase in the GSH and GSSG contents than those treated with $50 \mathrm{C}$ stress treatment alone (Figure 8E$8 \mathrm{~F})$. The both GSH and GSSG contents increased in leaves treated with GLA alone.

\section{Discussion}

GLA is classified as a polyphenolic compound and is largely found in different food sources (Jajic et al., 2015). GLA and other polyphenolic compounds have two or more phenolic hydroxyl groups in their chemical structure and therefore they have been shown antioxidant effects in plants (Selmar and Kleinwächter, 2013). Such compounds are known to donate a proton from their $\mathrm{O}-\mathrm{H}$ bond through hemolytic cleavage and are shown to generate even a more stabilized phenoxyl radical. As a result of its feature, GLA is regarded as an antioxidant with high free radical scavenging effect (Jajic et al., 2015). In the literature, several biological activities of exogenous GLA application, such as antiviral, antifungal, anticancer and antioxidant, have been previously reported (Selmar and Kleinwächter, 2013). These reports largely focus on animals. Therefore, no information is known about the protective responses of exogenous GLA on the oxygen scavenging systems under cold stress and its reactive role in improving low temperature tolerance in plants.

Cold stress is one of the most important environmental variables affecting leaf growth (Janska et al., 2010). The results in this study showed that the inhibition in growth rate, RGR, increased under all the cold treatment, was more at the lowest temperature level. This reduction might connect to alter cell division rates in cells exposed to cold stress, as reported by Francis and Barlow (1988). Soybean with GLA application under cold stress induced growth rate. Similar results had been found in rice exposed to GLA plus salt and/or PEG stress by Ozfidan-Konakci et al. (2015). As plant RGR decreases, RWC is reduced and stomatal closure occurs which is paralleled by a decreased photosynthetic rate under stress conditions (Rosales et al., 2012). This result was consistent with our result. However, in this study, the capacity to maintain high RWC values (through close to control levels of leaf water loss) was observed in GLAtreated plants under stress. Soybean leaves possessed higher RWC as reflected in its higher water holding capacity. On the other hand, the results of the present work also suggested that improvement of tolerance on photosynthetic apparatus against cold stress by addition of GLA was observed in soybean leaves. Under stress, decrease of leaf RWC induces stomatal closure, leading to a reduction of $\mathrm{CO}_{2}$ availability and consequently to a decline in photosynthesis rate (Rosales et al., 2012; Mahdieh et al., 2015). Photosynthesis is a highly sensitive process to any change in environmental conditions, especially extreme temperatures, because it is essential to maintain the balance between light energy absorbed by photosystems and energy consumed by metabolic sinks in the plant. The change in $\Phi_{\text {PSII }}$ relates to the change in carboxylation efficiency resulting from a downstream regulating mechanism (Ogweno et al., 2008). Also, a slight increase in qP of soybean with GLA plus stress treatments could be attributed to an increase in the rate of reductant consumption and ATP produced by noncyclic electron transport relative to the rate of excitation of open PSII reaction centers, as reported by Nogues and Baker (2000). In this study it is shown that GLA application might contribute to protection 
carboxylation in photosynthesis and resulted in less dissipation of excitation energy in the PSII antennae. As observed by Ogweno et al. (2008), NPQ increased markedly in stressed soybean leaves resulting in a loss of integrity in the thylakoid membrane. However, depending on decreasing in NPQ of plants with GLA application under stress conditions, it was prevented the over excitation of the PSII. The significant positive correlations between production of phenolics acid and photosynthesis, stomatal conductance and apparent quantum yield.

Osmotic adjustment is created from the accumulation of compatible solutes in the cells such as sugar, proline, minerals alcohols and glycine betaine (Mattioli et al., 2009). The decrease in $\Psi$ п of stress-treated soybean leaves corresponded to a degree of osmotic adjustment. The capacity to accumulate great quantities of Pro content, which participate in the reduction of $\Psi \Pi$ and in osmotic adjustment, could be only explained with $5{ }^{\circ} \mathrm{C}$ cold treatment. So, the reduced $\Psi п$ levels observed in $10{ }^{\circ} \mathrm{C}$-treated plants might connect to the other compatible compounds except Pro content. Pro accumulation may help to maintain the relatively high water content necessary for growth and cellular function (Mattioli et al., 2009). Although GLA application with stress treatments increased growth, RWC and $\Psi_{\Pi}$, the induced Pro accumulation could not achieve with GLA plus stress. OzfidanKonakci et al. (2015) also reported that $\mathrm{NaCl}$ plus GLA did not cause an increase in Pro content in rice, but PEG plus GLA did. Therefore, the responses to the different stress conditions in terms of Pro accumulation have changed in plants.

Exposure to low temperature may result in the increased generation of ROS in plants (Zhang et al., 2014). It is well known that exposure of soybean leaves to cold stress resulted the toxic $\mathrm{H}_{2} \mathrm{O}_{2}$ levels that occurred to the diminished activity of, CAT and POX. Our experiments demonstrated that the major part of the reduced total SOD activity in all stress treatments was due to the decrease in Fe-SODs activity, as compared to control groups. When stress cause loss of CAT activity, the activities of the Halliwell-Asada pathway enzymes such as APX and GR induces (Zhang et al., 2014). As compatible to this expression, the lower cold stress caused an increase in APX and GR activity in soybean. Similarly, Oidaira et al. (2000) reported that low temperature stress induces a rapid increase in APX activity but, CAT activity was not significantly affected by stress in rice. It can be hypothesized that increased accumulation of $\mathrm{H}_{2} \mathrm{O}_{2}$ under stress might be caused by this decline in CAT and POX activity and also related to other $\mathrm{H}_{2} \mathrm{O}_{2}$ resources except SOD activity in soybean. It was observed that cold stress induced production of $\mathrm{H}_{2} \mathrm{O}_{2}$ in the leaves of eggplants (Chen et al., 2011). Nauseef (2014) previously reported that NOX induced ROS accumulation under stress conditions. Similarly, in soybean leaves treated with stress, NOX activity was enhanced. However, it is interesting to note that GLA treatment under stress (especially at $5{ }^{\circ} \mathrm{C}$ ) could supply the increased activity of SOD, CAT, APX and GR and decreased NOX activity. Therefore, the reduction in $\mathrm{H}_{2} \mathrm{O}_{2}$ accumulation under GLA plus stress could be related to both the increased these antioxidant enzymes and decreased NOX activity in soybean.

The antioxidant defense system is also composed of the ascorbate-glutathione cycle, consisting of two major non-enzymatic antioxidants, AsA and GSH, and four enzymes, APX, MDHAR, DHAR and GR. These enzymes help AsA and GSH scavenge major ROS and regenerate in their active, reduced form through spontaneous biochemical reactions. GR catalyzes the NADPH-dependent reduction of oxidised glutathione (GSSG) to reduced glutathione (GSH) and thus keeps the GSH/GSSG ratio high (Asada, 1999). In agreement with this idea, GLA-treated soybean leaves which showed higher APX and GR activity 
during stress treatment $\left(5{ }^{\circ} \mathrm{C}\right)$ appeared to have a higher ability to decompose $\mathrm{H}_{2} \mathrm{O}_{2}$ (connected with decreased $\mathrm{H}_{2} \mathrm{O}_{2}$ content) and catalyze the reduction of GSSG to GSH (related to increased GSH content). However, it did not exhibit a clear effect on the enzyme activity of GR under GLA plus 10 ${ }^{\circ} \mathrm{C}$ cold treatment. This observation is in agreement with earlier reports that GLA plus $\mathrm{NaCl}$ stress exhibit lowered GR activity in rice cultivars Pokkali (Ozfidan-Konakci et al., 2015). Low temperature stress resulted in increased AsA and GSH levels in cucumber leaves (Li et al., 2011). Conversely, in the present study, the AsA and GSH levels decreased in soybean under stress. This result might be due to declined MDHAR and DHAR activities. In plants, MDHAR and DHAR are responsible for regenerating AsA and play an important role in antioxidant defense. Leterrier et al. (2007) also showed that in pea plants exposed to low temperature stress for 48 $\mathrm{h}$, MDHAR activity did not show any significant change. Besides, compared with seedlings under cold stress alone, seedlings treated with GLA plus stress (especially at $10{ }^{\circ} \mathrm{C}$ ) unchanged or declined the activities of the above-mentioned enzymes. The result may be relevant to the extent that GLA in plants with $10{ }^{\circ} \mathrm{C}$ cold stress was insufficient to enhance the AsA recycling pathway, which means the activities of DHAR, MDHAR and GR were lower than that under cold stress group. However, only GLA (GLA1 and GLA2) plus low temperature stress $\left(5^{\circ} \mathrm{C}\right)$ caused an increase in the activities of MDHAR and DHAR and the contents of DHA and AsA. Exogenous GLA increased AsA level in soybean leaves under low temperature stress, mainly owing to the activity of the DHAR enzyme. Stevens (2008) concluded that the induction activity of MDHAR in tomato contributes to stress tolerance during exposure to cold stress. Wang et al. (2010) also concluded that induction of AsA content through the enhanced recycling pathway reduces the deleterious effects of environmental stress.

A higher lipid peroxidation resulting from damage induced by cold stress was also reported on Digitaria eriantha (Garbero et al., 2011). Lipid peroxidation induced by stress is experimentally expressed as the level of TBARS. This enhancement of peroxidation is known to be exacerbated by $\mathrm{OH}^{\bullet}$ accumulation that may be generated through Fenton-type reactions (Asada, 1999). In this study, there is a positive correlation between increased TBARS content and decreased scavenging activity of $\mathrm{OH}^{\bullet}$ under cold stress. However, GLA application under both the temperature treatments caused a decrease in lipid peroxidation on membranes, as suggested by a strong decline in TBARS of GLA-treated plants exposed to cold stress. The results of the present experiment were in line with the findings of Ozfidan-Konakci et al. (2015). It is closely related that after GLA application under stress, it is observed both the reduction of TBARS content and the induced scavenging of $\mathrm{OH}^{\bullet}$. The scavenging of the $\mathrm{OH}^{\bullet}$ might be due to the presence of hydrogen donating ability phenolic compounds. This result showed that the mechanism of GLA might directly combine with free radicals and lead to inactivate them.

In conclusion when comparing to the stress treatments alone, the damage induced by the lower temperature stress was more pronounced than the higher one. The results of growth, water content, Pro content, photosynthetic activity and the scavenging activity of $\mathrm{OH}^{\bullet}$ decreased and $\mathrm{H}_{2} \mathrm{O}_{2}$ content and the levels of lipid peroxidation increased under stress conditions. Exogenous GLA application under cold stress was involved in the protection of the photosynthetic apparatus and water status in soybean. After exposure to stress (both at $5{ }^{\circ} \mathrm{C}$ and $10{ }^{\circ} \mathrm{C}$ ), GLA-treated plants exhibited higher the tolerance against stress by increased the activity of SOD and CAT. Also, an interesting result 
observed that the both GLA concentrations under $5^{\circ} \mathrm{C}$ stress efficiently activated the antioxidant metabolism through enzyme activities of SOD, CAT, APX and GR and, contents of DHA, AsA and GSH and activities of MDHAR and DHAR in ascorbate-glutathione cycle. GLA exhibited higher potency of free radical scavenging activity which is highly related to the presence of hydroxyl groups. Therefore, GLA was identified as a versatile scavenger, capable of rapidly deactivating a wide variety of ROS via electron transfer.

\section{Acknowledgements}

Financial support for this work was provided by Selcuk University Scientific Research Projects Coordinating Office (Project Number: 14401032).

\section{References}

Asada, K. 1999. The water-water cycle in chloroplasts: scavenging of active oxygens and dissipation of excess photons. Annu Rev. Plant Physiol. Plant Mol. Biol. 50, 601-639.

Bates, L., Waldrenn, R., Teare, I. 1973. Rapid determination of free proline for water-stress studies. Plant Soil. 39, 205-207.

Bergmeyer, N. 1970. Methoden der enzymatischen analyse, vol. 1. Akademie Verlag, Berlin.

Bose, J., Rodrigo-Moreno, A., Shabala, S. 2014. ROS homeostasis in halophytes in the context of salinity tolerance. J. Exp. Bot. 65, 1241-1257.

Bunn, R., Lekberg, Y., Zabinski, C. 2009. Arbuscular mycorrhizal fungi ameliorate temperature stress in thermophilic plants. Ecology. 90, 1378-1388.

Chen, S., Zimei, L., Cui, J., Jiangang, D., Xia, X., Liu, D., Yu, J. 2011. Alleviation of chilling-induced oxidative damage by salicylic acid pretreatment and related gene expression in eggplant seedlings. Plant Growth Regul. 65, 101-108.

Chung, S.K., Osawa, T., Kawakishi, S. 1997. Hydroxyl radical-scavenging effects of spices and scavengers from brown mustard (Brassica nigra). Biosci. Biotech. Bioch. 61, 118-123.

Dalton, D.A., Russell, S.A., Hanus, F.J., Pascoe, G.A., Evans, H.J. 1986. Enzymatic reactions of ascorbate and glutathione that prevent peroxide damage in soybean root nodules. P. Natl. Acad. Sci. USA. 83, 3811-3815.

Dutilleul, C., Driscoll, S., Cornic, G., De Paepe, R., Foyer, C.H., Noctor, G. 2003. Functional mitochondrial complex I is required by tobacco leaves for optimal photosynthetic performance in photorespiratory conditions and during transients. Plant Physiol. 131(1), 264-275.

Francis, D., Barlow, P.W. 1988. Temperature and the cell cycle. In SP Long, FI Woodward, (eds.) Plants and Temperature, 42nd Symposium of the Society for Experimental Biology. Company of Biologists, Cambridge, UK. 181-201.

Garbero, M., Pedranzani, H., Zirulnik, F., Molina, A., Pérez-Chaca, M.V., Vigliocco, A., Abdala, G. 2011. Short-term cold stress in two cultivars of Digitaria eriantha: Effects on stress-related hormones and antioxidant defense system. Acta Physiol. Plant. 33, 497-507.

Jajic, I., Sarna, T., Strzalka, K. 2015. Senescence, Stress, and Reactive Oxygen Species. Plants. 4, 393-411.

Janska, A., Marsik, P., Zelenkova, S., Ovesna, J. 2010. Cold stress and acclimation-what is important for metabolic adjustment?. Plant Biol. (Stuttg.). 12, 395-405.

Leterrier, M., del Río, L.A., Corpas, F.J. 2007. Cytosolic NADP-isocitrate dehydrogenase of pea plants: genomic clone characterization and func- 
tional analysis under abiotic stress conditions. Free Radic. Res. 41, 191-199.

Li, Q., Yu, B., Gao, Y., Dai, A.H., Bai, J.G. 2011. Cinnamic acid pretreatment mitigates chilling stress of cucumber leaves through altering antioxidant enzyme activity. J. Plant Physiol. 168, 927-934.

Mahdieh, M., Habibollahi, N., Amirjani, MR., Abnosi, M.H., Ghorbanpour, M. 2015. Exogenous silicon nutrition ameliorates salt-induced stress by improving growth and efficiency of PSII in Oryza sativa L. cultivars. J. Soil Sci. Plant Nutr. 15(4), 1050-1060.

Mandal, S.M., Chakraborty, D., Dey, S. 2010. Phenolic acids act as signaling molecules in plant-microbe symbioses. Plant Signal Behav. 5, 359-368.

Mattioli, R., Falasca, G., Sabatini, S., Altamura, M.M., Costantino, P., Trovato, M. 2009. The proline biosynthetic genes P5CS1 and P5CS2 play overlapping roles in Arabidopsis flower transition but not in embryo development. Physiol. Plant. $137,72-85$.

Miyake, C., Asada, K. 1992. Thylakoid-bound ascorbate peroxidase in spinach chloroplasts and photoreduction of its primary oxidation product monodehydroascorbate radicals in thylakoids. Plant Cell Physiol. 33, 541-553.

Nauseef, W.M. 2014. Detection of superoxide anion and hydrogen peroxide production by cellular NADPH oxidases. Biochim. Biophys. Acta. 1840, 757-767.

Nogués, S., Baker, N.R. 2000. Effects of drought on photosynthesis in Mediterranean plants grown under enhanced UV-B. J. Exp. Bot. 51, 1309-1317.

Ogweno, J., Song, X., Shi, K., Hu, W., Mao, W., Zhou, Y., Yu, Y.Q., Nogués, S. 2008. Brassinosteroids alleviate heat-induced inhibition of photosynthesis by increasing carboxylation efficiency and enhancing antioxidant systems in $L y$ - copersicon esculentum. J. Plant Growth Regul. 27, 49-57.

Oidaira, H., Satoshi, S., Tomokazu, K., Takashi, U. 2000. Enhancement of antioxidant enzyme activities in chilled rice seedlings. Plant Physiol. 156, 811-813.

Ozfidan-Konakci, C., Yildiztugay, E., Kucukoduk, M. 2015. Protective roles of exogenously applied gallic acid in Oryza sativa subjected to salt and osmotic stresses: effects on the total antioxidant capacity. Plant Growth Regul. 75(1), 219-234.

Ozgur, R., Turkan, I., Uzilday, B., Sekmen, A.H. 2014. Endoplasmic reticulum stress triggers ROS signalling, changes the redox state, and regulates the antioxidant defence of Arabidopsis thaliana. J. Exp. Bot. 65, 1377-1390.

Paradiso, A., Berardino, R., Pinto, M.C., Toppi, L.S., Storelli, M.M., Tommasi, F., Gara, L. 2008. Increase in ascorbate-glutathione metabolism as local and precocious systemic responses induced by cadmium in durum wheat plants. Plant Cell Physiol. 49, 362-374.

Pennycooke, J.C., Cox, S., Stushnoff, C. 2005. Relationship of cold acclimation, total phenolic content and antioxidant capacity with chilling tolerance in petunia (Petunia $x$ hybrida). Environ. Exp. Bot. 53, 225-232.

Rosales, M.A., Ocampo, E., Rodríguez-Valentín, R., Olvera-Carrillo, Y., Acosta-Gallegos, J., Covarrubias, A.A. 2012. Physiological analysis of common bean (Phaseolus vulgaris L.) cultivars uncovers characteristics related to terminal drought resistance. Plant Physiol. Bioch. 56, 24-34.

Sagi, M., Fluhr, R. 2006. Production of reactive oxygen species by plant NADPH oxidases. Plant Physiol. 141(2), 336-340.

Selmar, D., Kleinwächter, M. 2013. Stress enhances the synthesis of secondary plant products: the impact of stress-related over-reduction on the accu- 
Stevens, R., Page, D., Gouble, B., Garchery, C., Zamir, D., Causse, M. 2008. Tomato fruit ascorbic acid content is linked with monodehydroascorbate reductase activity and tolerance to chilling stress. Plant Cell Environ. 31, 1086-1096.

Toorchi, M., Yukawa, K., Nouri, M.Z., Komatsu, S. 2009. Proteomics approach for identifying osmotic-stress-related proteins in soybean roots. Peptides. 30, 2108-2117.

Van Heerden, P.D.R., Tsimilli-Michael, M., Kruger, G.H.J., Strasser, R.J. 2003. Dark chilling effects on soybean genotypes during vegetative development: parallel studies of $\mathrm{CO}_{2}$ assimilation, chlorophyll a fluorescence kinetics O-J-I-Pand nitrogen fixation. Physiol. Plant. 117, 476-491.
Wang, Z., Xiao, Y., Chen, W., Tang, K., Zhan, L. 2010. Increased vitamin $C$ content accompanied by an enhanced recycling pathway confers oxidative stress tolerance in Arabidopsis. J. Integr. Plant Biol. 52, 400-409.

Zhang, X., Yin, H.B., Chen, S.H., He, J., Guo, S.L. 2014. Changes in antioxidant enzyme activity and transcript levels of related genes in Limonium sinense Kuntze seedlings under $\mathrm{NaCl}$ stress. J. Chem. 749047. 